RESEARCH REPORT

\title{
Increasing inequalities in premature mortality in Great Britain
}

\section{A H Leyland}

Correspondence to: Dr A H Leyland, MRC Social and Public Health Sciences Unit, University of Glasgow, 4 Lilybank Gardens, Glasgow G12 8RZ, UK; a.leyland@ msoc.mrc.gla.ac.uk

\begin{abstract}
Study objective: To describe inequalities in all cause premature mortality between and within regions of Great Britain and how these inequalities have changed between 1979 and 1998.

Design: Retrospective study using routine population and death data aggregated into five year age and sex groups for each of 20 years.

Setting: All 459 local authority districts (England and Wales) and local government districts (Scotland).

Participants: Estimated population and registered deaths aged 0-64.

Main outcome measures: Indirectly standardised mortality ratios for all cause mortality; percentages of deaths that would be avoided if there were no inequalities between and within regions.

Results: The decrease in premature mortality of $36 \%$ seen in Great Britain ranged from $42 \%$ in Wales to $33 \%$ in Scotland and $31 \%$ in London. Differences between regions led to excess mortality of about $25 \%$ in Scotland, the North East, and the North West. In London excess mortality increased from 14\% to $19 \%$. Inequalities within regions increased in most parts of Great Britain, the exceptions being Wales, London, and the South West. The largest increase was seen in Scotland where the percentage of excess deaths increased from $23 \%$ to $33 \%$.

Conclusions: A decrease in premature mortality in Great Britain was seen in all regions, although less pronounced in London, but the gap between regions remained. Inequalities between districts within regions vary from one region to another and have increased in nearly every part of Great Britain.
\end{abstract}

1951 and 1981 in Scotland than in England and Wales. ${ }^{12}$ Furthermore, mortality differentials between populations living in the most and least socioeconomically deprived areas increased between 1981 and 1991 in Scotland ${ }^{13}$ and the north of England. ${ }^{14}$ A comparison of the mortality of the $10 \%$ of the population living in areas with the highest and lowest mortality rates indicated an increasing differential from the 1950 s to the $1990 \mathrm{~s},{ }^{15}$ in absolute and relative terms. ${ }^{16}$

Geographical inequalities in mortality have increased internationally at differing levels of aggregation. In the 20 years from 1978 life expectancy increased by five years in high income countries but remained unchanged in low and middle income countries. ${ }^{17}$ In the Netherlands there was some increase in regional inequalities in total mortality for men and women between 1972 and 1982. ${ }^{18}$ Between the early 1980s and the early 1990s inequalities have also increased between local administrative districts in Budapest, ${ }^{19}$ electoral wards in Barcelona, ${ }^{20}$ and small areas in an anonymous "large Swedish city". ${ }^{21}$ Similarly, regional inequalities in mortality increased in Manitoba between the late 1980s and early 1990s. ${ }^{22}$ The picture from Australia seems mixed; while inequalities have increased between local government areas in Sydney ${ }^{23}$ (between 1972 and 1992) and New South Wales ${ }^{24}$ (1972 to 1987), at a national level increasing inequalities were limited to males aged 0-24 between 1986 and 1996, with other ages and females showing no change or decreasing inequalities. ${ }^{25}$

This paper describes the contribution to the mortality rate of inequalities between regions and inequalities within regions, and illustrates how these inequalities have changed using annual data from 1979 to 1998.

Abbreviations: SMR, standardised mortality rate; LGR, local government reorganisation investigation of relative inequalities in mortality suggesting the social class gradient had increased more rapidly between 


\section{METHODS}

Deaths from all causes by five year age groups and sex for local authorities in England and Wales on an annual basis were obtained from the Vital Statistics Tables of the Office for National Statistics (ONS) from 1979 to 1998; mid-year population estimates (also from the ONS) were used to provide denominator populations. A comparable dataset was assembled for Scotland from death records and population estimates from the General Register Office for Scotland. Analysis was restricted to deaths among the population aged less than 65; a summary of these data is provided in table 1. An increase of $4.1 \%$ in the population aged less than 65 was accompanied by a $32.8 \%$ decline in the number of deaths, meaning that by 1998 there were about 12 fewer deaths per 10000 population than in 1979. The largest decreases were seen in the older age groups.

The data refer to populations living in local authority districts (England and Wales) or local government districts (Scotland). These are the basic units of the analysis and, although far from homogenous in terms of their populations, they reflect substantial differences in terms of their compositions. ${ }^{26}$ In 1979 there were 459 such districts. These districts are clustered within the nine regions of England plus Scotland and Wales; however, the intermediate level of county in England and Wales and Health Board in Scotland is also considered. London is considered to be a single county (as well as being a region); it was broken down into five pseudo-counties based on the Nomenclature of Units for Territorial Statistics (NUTS3) areas. ${ }^{27}$ (As the counties of England and Wales are NUTS3 areas, this creates a standard unit.) These will enable us to determine whether regional variations arise due to the clustering of districts of similar mortality within counties; there were a total of 73 counties in 1979.

The data contain a number of hierarchies. Repeated measures (the number of deaths) were available for each of 20 years in each district. As some districts always tend to have mortality rates that are higher or lower than average, the observations on each district are clearly correlated (just as they would be if repeated measures were made on an individual). Moreover, the districts are nested within counties and the counties within regions. Mortality rates for all of the districts within the same county are likely to be correlated, as are those for all counties within a particular region. Multilevel modelling ${ }^{28}{ }^{29}$ was used to take account of these hierarchies and allow for persistently high (or low) mortality rates in some regions (in contrast with random fluctuations from one year to another). This enabled the partitioning of the variation between districts to that part attributable to each of the district, county and region levels. The multilevel Poisson regression model applied used as an offset the expected number of deaths in each year in each

Table 1 Summary statistics for premature mortality in Great Britain, 1979-1998

\begin{tabular}{|c|c|c|}
\hline & 1979 & 1998 \\
\hline Population $<65$ & 46547810 & 48452162 \\
\hline Deaths $<65$ & 155628 & 104640 \\
\hline \multicolumn{3}{|l|}{$\begin{array}{l}\text { Deaths per } 10000 \\
\text { population }\end{array}$} \\
\hline men $<40$ & 10.8 & 8.3 \\
\hline $40-64$ & 105.7 & 60.4 \\
\hline women $<40$ & 6.8 & 4.6 \\
\hline $40-64$ & 61.2 & 38.0 \\
\hline Regions & 11 & 11 \\
\hline Counties & 73 & 73 \\
\hline Districts & 459 & 432 \\
\hline
\end{tabular}

district (based on the 1998 age and sex specific mortality rates for Great Britain) and was therefore equivalent to modelling indirectly standardised rates. ${ }^{30}$ The software used was MLwiN ${ }^{31}$; further details of the methodology can be found elsewhere. ${ }^{32}$ Variance components were estimated from the model with the levels of year (observation), district, county and region; however, as there were only 11 regions these were treated as fixed effects as compared with random effects in the models reported (that is, a dummy variable was included for each region).

A trend was fitted to allow for changes over time. The SMRs reported in this paper are those estimated from this trend; using the data for all years in this way has the advantage over the observed SMR for a single year of smoothing out random fluctuations around the trend. The variation between districts within each region is summarised by a standard deviation. As a Poisson multilevel model has been fitted these standard deviations are on the same scale as the log rate ratio. The trend was found to vary significantly between districts, counties, and regions; this meant that the standard deviations changed over time. If the standard deviation is unchanged it implies that the relative dispersion of districts is unchanged (and, with falling mortality rates, this will imply a reduction in the absolute variation).

Local government reorganisation (LGR) between 1995 and 1998 created new unitary authorities; old districts were merged and split as part of this process. ${ }^{27}$ The death records used in Scotland included both pre-LGR and post-LGR areas of residence; however, the aggregated mortality data in England and Wales were provided using boundaries in existence that year. The impact of these changes, shown in table 1, was a reduction in the number of districts from 459 in 1979 to 432 in 1998. As the trends in the mortality rates in individual areas - and the variance between areas-are of interest, a multiple membership model ${ }^{33}$ was used to take account of the geographical changes. In essence, this entails modelling the relative risk of mortality associated with each of the new areas through the weighted sum of the risks for the pre-LGR areas. The weights used were according to the populations in the pre-LGR and post-LGR areas.

\section{RESULTS}

Between 1979 and 1998 the mortality rate (standardised to the European standard population) for Great Britain fell from 348 to 219 per 100000 population aged 0-64 (table 2). Over this time the standard error of the district mortality ratespresented as a measure of variation-decreased from 59 to 48. Although the standard error decreased in absolute terms, the fact that this decrease was smaller than that seen for the mortality rate implies that relative inequalities increased. Also shown in table 2 are the mortality rates and standard errors for each region.

The SMR in 1979 for the whole of Great Britain was 157 (based on 1998 mortality rates); the 19 years therefore saw a $36.4 \%$ reduction in age and sex standardised mortality rates. This reduction was not uniform across regions; figure 1 shows yearly SMRs based on national mortality rates in 1998 . The reduction in SMR was most marked in Wales-from an above average 165 in 1979 to a below average 96 in 1998, a decrease of $41.9 \%$. The decrease in mortality was relatively slower in Scotland (from 191 to 128 , a reduction of $33.1 \%$ ) and London ( 150 to $103,31.4 \%$ ).

Figure 1 describes the differences between regions; however, this is only part of the picture. There are also considerable disparities in mortality between districts within the same region. Table 3 shows the districts with the highest and lowest SMRs in 1979 and 1998 in each region. The SMRs given in this table are predicted SMRs, based on long term trends in each district and therefore not subject to year on 
Table 2 Directly standardised mortality rates per 100000 population aged 0-64, together with the standard error of the district mortality rates, 1979 and 1998, for all regions and for Great Britain

\begin{tabular}{|c|c|c|c|c|}
\hline \multirow[b]{2}{*}{ Region } & \multicolumn{2}{|l|}{1979} & \multicolumn{2}{|l|}{1998} \\
\hline & $\begin{array}{l}\text { Mortality per } \\
100000 \text { aged } \\
0-64\end{array}$ & $\begin{array}{l}\text { Standard error of } \\
\text { district mortality } \\
\text { rates }\end{array}$ & $\begin{array}{l}\text { Mortality per } \\
100000 \text { aged } \\
0-64\end{array}$ & $\begin{array}{l}\text { Standard error of } \\
\text { district mortality } \\
\text { rates }\end{array}$ \\
\hline Scotland & 422 & 67 & 279 & 60 \\
\hline North East & 402 & 33 & 254 & 31 \\
\hline North West & 394 & 44 & 250 & 44 \\
\hline London & 335 & 52 & 226 & 42 \\
\hline York and Humber & 363 & 42 & 226 & 40 \\
\hline West Midlands & 354 & 44 & 219 & 31 \\
\hline Wales & 363 & 40 & 210 & 24 \\
\hline East Midlands & 333 & 32 & 208 & 34 \\
\hline South East & 295 & 34 & 186 & 44 \\
\hline South West & 304 & 39 & 186 & 27 \\
\hline East of England & 290 & 31 & 185 & 31 \\
\hline Great Britain & 348 & 59 & 219 & 48 \\
\hline
\end{tabular}

year fluctuations. In every region there has been a greater reduction in mortality in districts with the lowest mortality rates than among those with the highest rates. The reductions in low mortality areas range from $77 \%$ in Scotland (from 137 to 77 ) to $47 \%$ in London; in high mortality areas they range from $37 \%$ in Wales to just $5 \%$ in Scotland. In general it has not been the same districts that have had the highest or lowest rates in both 1979 and 1998 . Also shown in table 3 are the standard deviations for districts within each region; these have increased for all regions by between 16\% (Wales) and 90\% (East Midlands). These increases suggest a pattern of increasing relative inequalities in all regions.

A variance components model was used to quantify the relative importance of differences between and within regions. The variation between regions accounted for $44 \%$ of the total variation in addition to random year on year fluctuations in district mortality rates. There was little variation $(17 \%)$ between counties within regions, with the remainder $(39 \%)$ arising because of differences between districts within counties.

Although a total of $56 \%$ of the variation in district mortality rates was attributable to differences within regions, this figure varied from one region to another. The relative importance of between regional variation and within regional variation for each region can be quantified in terms of the proportion of mortality that could be avoided if either of these sources of variation were to be eliminated and the other remained unchanged. Firstly, we consider reducing the average mortality rate in each region to that of the East of England-the region with the lowest SMR for most years in figure 1 . The relative pattern of inequalities within regions is assumed to be unchanged so that, for example, the relative risk of mortality in Glasgow City remains 2.82 times that in Eastwood in 1998 (as given in table 3). Figure 2 shows the proportion of deaths that would be eliminated in each region

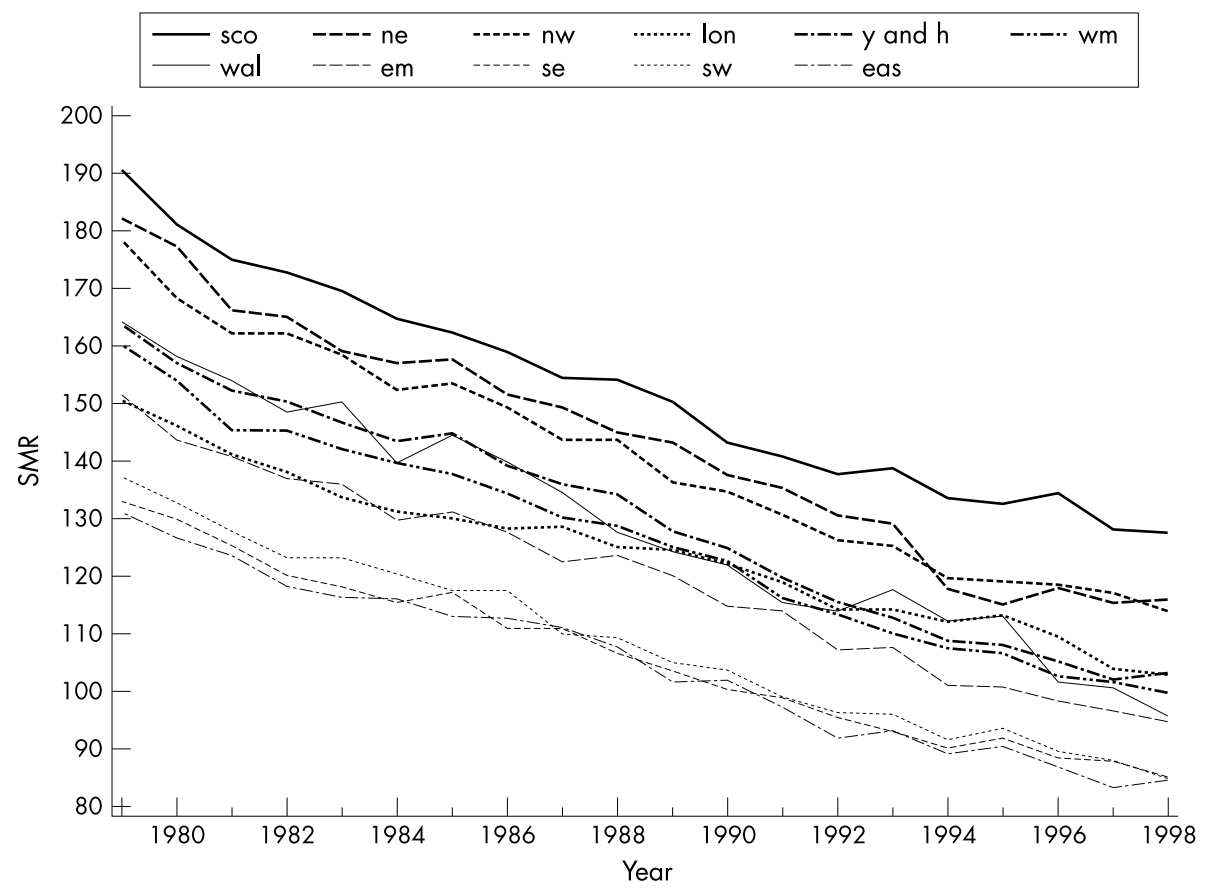

Figure 1 SMR for country and region, 1979-1998 (SMR for GB 1998= 100). sco, Scotland; ne, North East; nw, North West; lon, London; $y$ and h, York and Humber; wm, West Midlands; wal, Wales; em, East Midlands; se, South East; sw, South West; eas, East of England. 


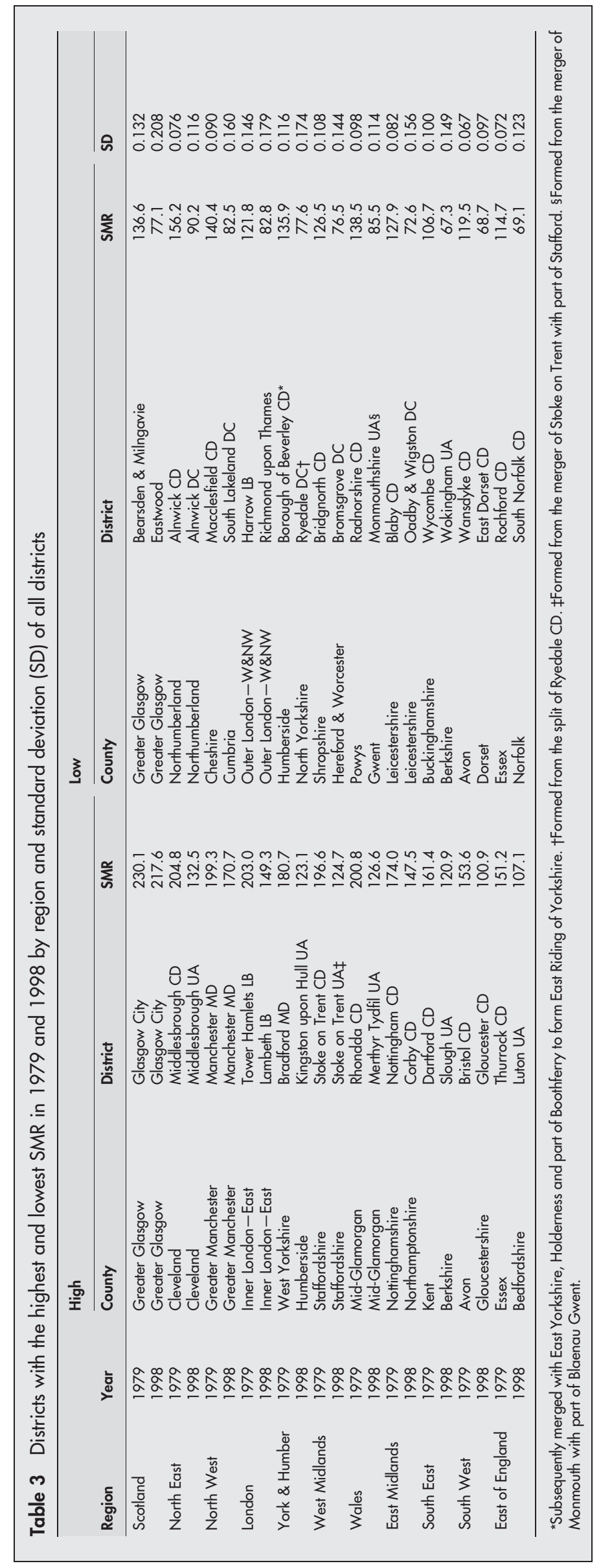




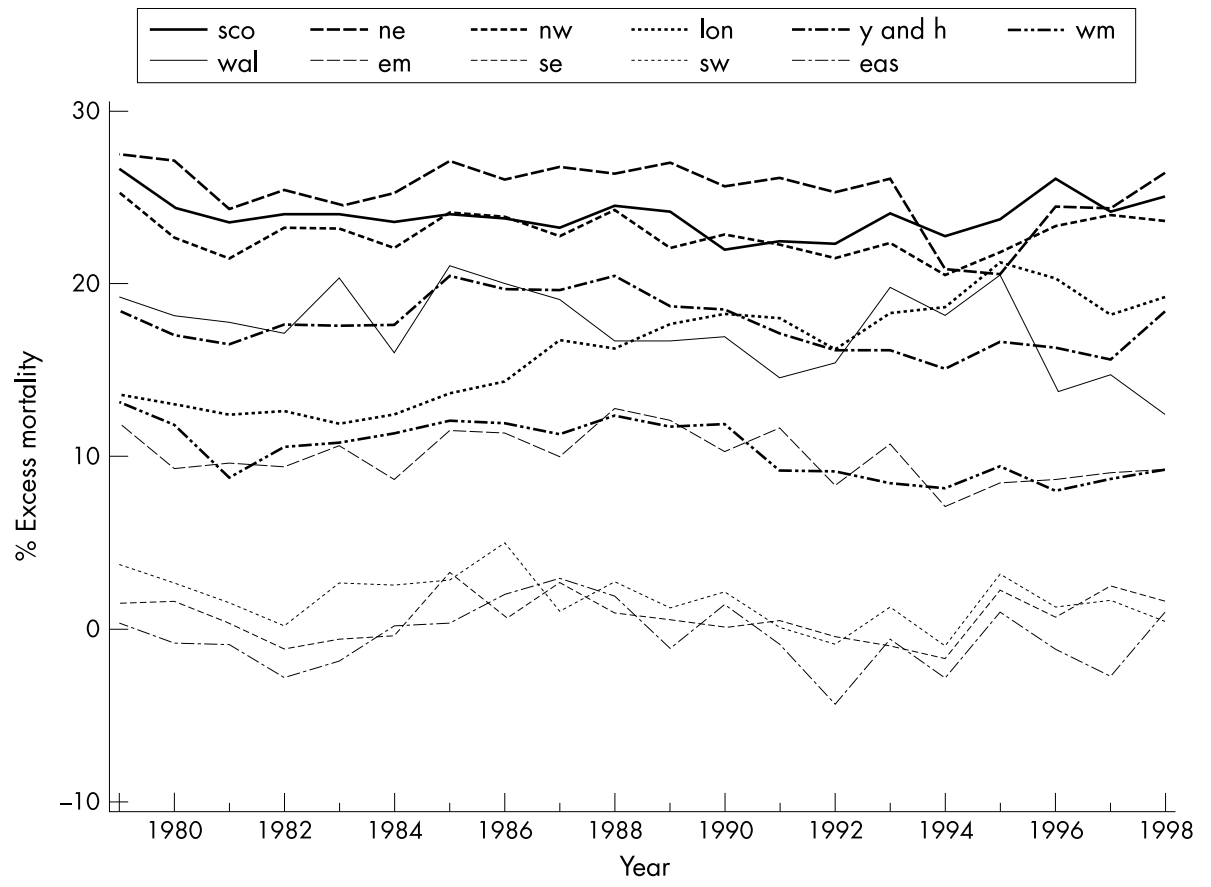

Figure 2 Percentage of deaths that would be avoided if differences between regions were eliminated. sco, Scotland; ne, North East; nw, North West; lon, London; $y$ and $h$, York and Humber; wm, West Midlands; wal, Wales; em, East Midlands; se, South East; sw, South West; eas, East of England

in each year in this manner. The excess mortality is calculated as the proportional decrease in observed deaths that would result from having the same long term trend in the risk of mortality as the East of England. Yearly fluctuations in the observed deaths around the long term trend mean that the excess mortality in the East of England will not be exactly $0 \%$. Although some regions such as Wales decreased differences with the East of England, most maintained relative differentials. Excess mortality was about $25 \%$ in Scotland, the North East and the North West. There was a persistent increase in excess premature mortality in London, from $14 \%$ of all deaths under 65 in 1979 to $19 \%$ in 1998 .

Now we consider the effect of reducing the variation within regions. Figure 3 shows the proportion of deaths that would be eliminated in each region if all districts in that region had a mortality rate equivalent to the 10th centile of districts within that region. (It would be possible to choose any other centile, for example, the median or 50th centile. The choice of the 10th centile means that a fairly demanding target is being set.) The chosen centile is obtained from the

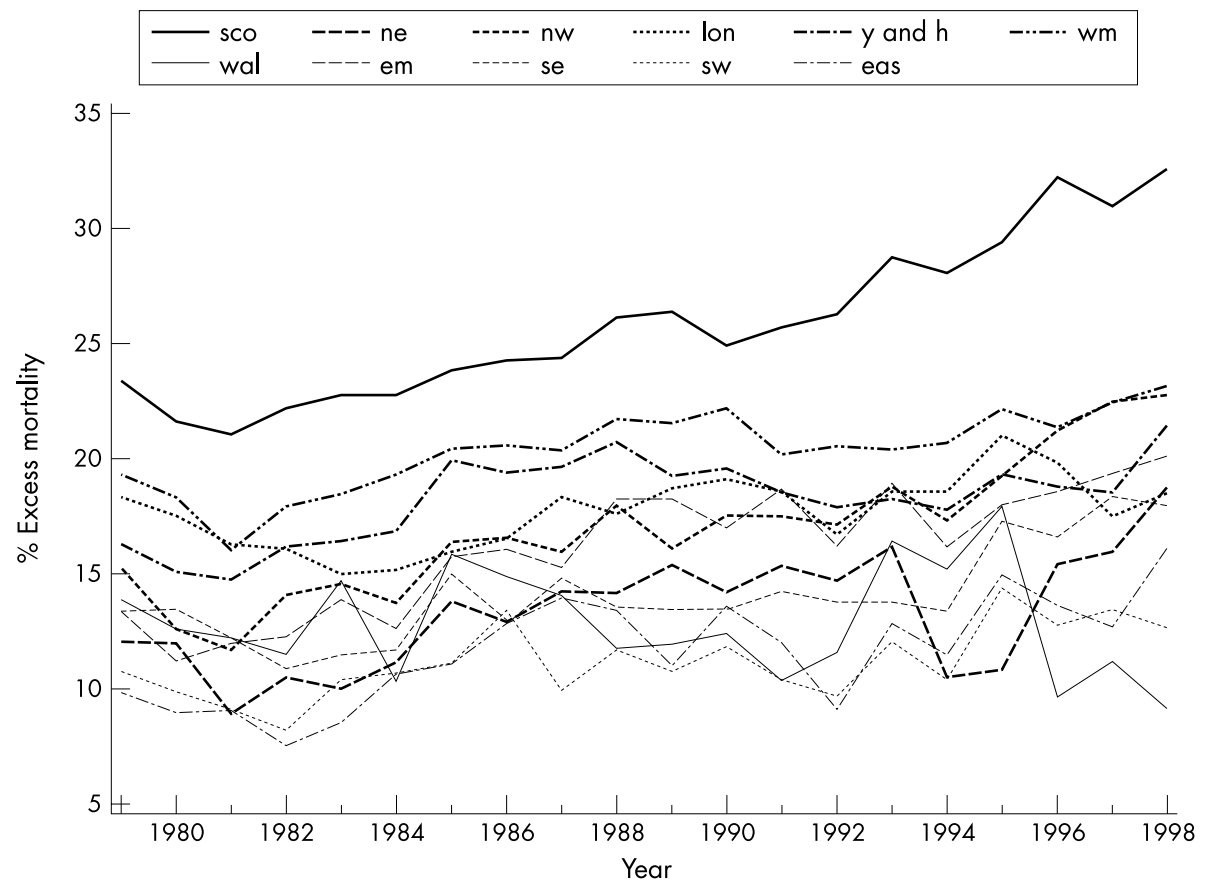

Figure 3 Percentage of deaths that would be avoided if differences within regions were eliminated. sco, Scotland: ne, North East; nw, North West; lon, London; $y$ and $h$, York and Humber; wm, West Midlands; wal, Wales; em, East Midlands; se, South East; sw, South West; eas, East of England 


\section{Key points}

- Mortality rates in Great Britain have decreased in all regions

- There are mortality differentials between regions of England and Scotland and Wales and between counties within these regions

- Differences in premature mortality between regions persisted between 1979 and 1998

- Differences between districts within regions have increased over the same time

- Inequalities between districts are greater in Scotland than in any other region

variance of all districts within the region. From figure 3 we can see that for most regions there was an increase in the proportion of excess deaths over the 20 years; the exceptions to this were a decline in Wales (from 14\% in 1979 to $9 \%$ in 1998 ) and little change in London (18\% to $19 \%$ ) and the South West ( $11 \%$ to $13 \%)$. Not only did Scotland have a higher percentage of excess deaths than any other region, but this proportion increased substantially from $23 \%$ to $33 \%$.

\section{DISCUSSION}

This paper has described changes over time in mortality rates and variation between districts in these rates. There has been no attempt to explain why this variation occurs; rather, the focus has been on the quantification of the variation in terms that are useful when considering inequalities in health. Many recent studies have focused on the relation between contextual (area) characteristics and health, with particular emphasis on social capital, ${ }^{34}$ socioeconomic deprivation or socioeconomic status, ${ }^{35-38}$ and area level income inequality. ${ }^{39-43}$ Such factors would provide suitable starting points when trying to explain why these inequalities exist, and the contribution of any of these to inequalities could then be assessed.

The overall pattern of a reduction in SMRs is encouraging, although there must be questions as to why the reductions have varied across regions. It is possible that, at least in part, some of these differences could be explained by compositional differences in terms of factors associated with widening mortality differentials such as social class. ${ }^{5}$ This would not account for the much slower decline in mortality seen in London compared with other regions; by 1998 the relative risk of mortality in London was $15 \%$ higher than would have been the case had mortality rates in London declined in line with other regions. Possible causes include variation introduced through differing patterns of selective migration, either from abroad ${ }^{44}$ or within Great Britain. ${ }^{45}$ This slow decline led to an increase in the relative risk of mortality

\section{Policy implications}

- Reducing inequalities in health has become a health priority in the UK and in many other countries. Although inequalities between regions attract frequent comment, the fact that inequalities between districts may vary from one region to another receives less attention. Any future reduction in inequalities must come against a background of increasing inequalities between areas. associated with living in London compared with the East of England, the region with the lowest mortality rates. Wales was the only region that closed the gap, with excess mortality falling from $19 \%$ to $12 \%$. Inequalities between regions remained unchanged elsewhere.

The reduction in mortality rates was less pronounced in regions with high mortality in 1979; however, this effect was small and made little contribution to mortality differentials. But within regions the gaps between the districts with the lowest and the highest mortality rates increased. As in general it is not the same district that has a high or low mortality rate in a region in 1979 and 1998, the rate at which area mortality rates diverged will be greater than that implied by a simple comparison of the areas in table 3 . This increasing polarisation as gaps have opened up between affluent and deprived or healthy and unhealthy areas has translated into increases in the proportion of excess deaths in most regions, with a particularly steep increase seen in Scotland.

Inequalities in health are undesirable and should be reduced when possible. ${ }^{46}$ Many European countries now have specific programmes designed to reduce inequalities in health $^{47}$; it is in recognition of this that the Department of Health recently included the reduction of geographical differences in life expectancy as one of their inequality targets. $^{48}$ The department acknowledges the difficulty in reaching the target-a reduction by at least $10 \%$ of the gap in average life expectancy at birth between the $20 \%$ of health authorities (in England and Wales) with the lowest life expectancy and the population as a whole-given current trends. The increase in inequalities in mortality between areas is not unique to Great Britain but is an international problem. As the health of certain areas worsens relative to the rest of the country it is important to bear in mind that such inequalities should be tackled nationally and not just at the area or community level. ${ }^{49} 50$

Mortality in Scotland is higher than in any region of England or Wales; about a quarter of premature deaths in Scotland would be avoided if Scotland had the same average mortality rate as the East of England. Research based on the early 1990s showed that only $60 \%$ of the difference between Scotland and England and Wales could be explained by deprivation-a finding termed the "Scottish effect". ${ }^{51}$ However, a larger and increasing proportion of deaths would be avoided if inequalities between districts within Scotland were eliminated. The failure of current levels of health spending to reduce either source of inequality should be borne in mind in the face of recent calls to abolish ${ }^{52}$ or even maintain ${ }^{53}$ subsidy through the Barnett formula.

\section{ACKNOWLEDGEMENTS}

I am very grateful to the anonymous referees for their comments on earlier versions of this paper.

Funding: The MRC Social and Public Health Sciences Unit is supported by the Chief Scientist Office of the Scottish Executive Health Department and the Medical Research Council

\section{REFERENCES}

1 Matheson J, Summerfield C. Social trends No 31. London: The Stationery Office, 2001.

2 Tickle L. Mortality trends in the United Kingdom, 1982 to 1992. Popul Trends 1996;86:21-8

3 Hattersley L. Expectation of life by social class. In: Drever F, Whitehead M, eds. Health inequalities. London: The Stationery Office, 1997.

4 Drever F, Bunting J. Patterns and trends in male mortality. In: Drever F, Whitehead M, eds. Health inequalities. London: The Stationery Office, 1997.

5 Acheson D. Independent inquiry into inequalities in health report. London: The Stationery Office, 1998.

6 Fitzpatrick J, Griffiths C, Kelleher M. Geographic inequalities in mortality in the United Kingdom during the 1990s. Health Statistics Quarterly 2000;7:18-31.

7 Drever F, Whitehead M. Mortality in regions and local authority districts in the 1990s: exploring the relationship with deprivation. Popul Trends 1995;82:19-26. 
8 Ecob R, Robertson C, Watt G. Has regional variation in mortality rates declined since 1931, and in all age groups, in Britain? A re-analysis using formal statistical modelling. J Epidemiol Community Health 1997;51:502-9.

9 Langford IH, Bentham G. Regional variations in mortality rates in England and Wales: an analysis using multilevel modelling. Soc Sci Med 1996;42:897-908

10 Fitzpatrick J, Griffiths C, Kelleher M, et al. Descriptive analysis of geographic variations in adult mortality by cause of death. In: Griffiths C, Fitzpatrick J, eds. Geographic variations in health. London: The Stationery Office, 2001:247-324

11 Griffiths C, Goldblatt P, Fitzpatrick J. Geographic variations in health: main findings and implications for the future. In: Griffiths C, Fitzpatrick J, eds. Geographic variations in health. London: The Stationery Office, 2001:359-68

12 Marang-van de Mheen P, Davey Smith G, Hart CL, et al. Socioeconomic differentials in mortality among men within Great Britain: time trends and contributory causes. J Epidemiol Community Health 1998;52:214-18.

13 McLoone P, Boddy FA. Deprivation and mortality in Scotland, 1981 and 1991. BMJ 1994;309:1465-70.

14 Phillimore $P$, Beattie A, Townsend P. Widening inequality of health in northern England, 1981-91. BMJ 1994;308:1125-8

15 Mitchell R, Dorling D, Shaw M. Inequalities in life and death. What if Britain were more equal? Bristol: The Policy Press, 2000.

16 Shaw M, Dorling D, Brimblecombe N. Changing the map: health in Britain 1951-91. In: Bartley M, Blane D, Davey Smith G, eds. The sociology of health inequalities. Oxford: Blackwell, 1998.

17 Sen K, Bonita R. Global health status: two steps forward, one step back. Lancet 2000;356:577-82.

18 Kunst A, Looman C, Mackenbach J. Socio-economic mortality differences in the Netherlands in 1950-1984: a regional study of cause-specific mortality. Soc Sci Med 1990;31:141-52.

19 Józan P, Forster D. Social inequalities and health: ecological study of mortality in Budapest, 1980-3 and 1990-3. BMJ 1999;318:914-15.

20 Borrell C, Plasència A, Pasarin I, et al. Widening social inequalities in mortality: the case of Barcelona, a southern European city. J Epidemiol Community Health 1997;51:659-67.

21 Malmström $M$, Sundquist J, Bajekal $M$, et al. Ten-year trends in all-cause mortality and coronary heart disease mortality in socio-economically diverse neighbourhoods. Public Health 1999;1 13:279-84

22 Mustard C, Derksen S, Black C. Widening regional inequality in premature mortality rates in Manitoba. Can J Public Health 1999:90:372-6.

23 Hayes L, Quine S, Taylor R, et al. Socio-economic mortality differentials in Sydney over a quarter of a century, 1970-94. Aust N Z J Public Health 2002;26:311-17

24 Quine S, Taylor R, Hayes L. Australian trends in mortality by socioeconomic status using NSW small area data, 1970-89. J Biosoc Sci 1995;27:409-19.

25 Turrell G, Mathers C. Socioeconomic inequalities in all-cause and specificcause mortality in Australia: 1985-1987 and 1995-1997. Int J Epidemiol 2001;30:231-9.

26 Wallace M, Denham C. The ONS classification of local and health authorities of Great Britain. London: HMSO, 1996.

27 ONS. Gazetteer of the old and new geographies of the United Kingdom. London: Office for National Statistics, 1999.

28 Goldstein H. Multilevel statistical models. London: Edward Arnold, 1995

29 Leyland AH, Goldstein H. Multilevel modelling of health statistics. Chichester: Wiley, 2001
30 Langford IH, Day RJ. Poisson regression. In: Leyland AH, Goldstein H, eds. Multilevel modelling of health statistics. Chichester: Wiley, 2001

31 Rasbash J, Healy M, Browne W, et al. MLwiN v1.01. London: Multilevel Models Project, Institute of Education, 1999.

32 Leyland AH, McLeod A. Mortality in England and Wales, 1979-1992: an introduction to multilevel modelling using MLwiN. Glasgow: MRC Social and Public Health Sciences Unit, 2000.

33 Hill PW, Goldstein H. Multilevel modelling of educational data with crossclassification and missing identification of units 1998;23:117-28.

34 Skrabski Á, Kopp M, Kawachi I. Social capital in a changing society: cross sectional associations with middle aged female and male mortality rates. J Epidemiol Community Health 2003;57:114-19.

35 Diez-Roux AV, Nieto FJ, Muntaner C, et al. Neighbourhood environments and coronary heart disease: a multilevel analysis. Am J Epidemio 1997; 146:48-63.

36 Reijneveld SA, Schene AH. Higher prevalence of mental disorders in socioeconomically deprived urban areas in the Netherlands: community of personal disadvantage? J Epidemiol Community Health 1998;52:2-7.

37 Bosma H, van de Mheen HD, Borsboom GJJM, et al. Neighbourhood socioeconomic status and all-cause mortality. Am J Epidemiol $2001 ; 153: 363-71$

38 Veugelers PJ, Yip AM, Kephart G. Proximate and contextual socioeconomic determinants of mortality: multilevel approaches in a setting with universal health care coverage. Am J Epidemiol 2001;154:725-32.

39 Kawachi I, Kennedy BP. The relationship of income inequality to mortality: does the choice of indicator matter? Soc Sci Med 1997;45:1121-7.

40 Ross NA, Wolfson MC, Dunn JR, et al. Relation between income inequality and mortality in Canada and in the United States: cross sectional assessment using census data and vital statistics. BMJ 2000;320:898-902.

41 Lochner K, Pamuk E, Makuc D, et al. State-level income inequality and individual mortality risk: a prospective, multilevel study. Am J Public Health 2001;91:385-91.

42 Mackenbach JP. Income inequality and population health. BMJ 2002;324:1-2.

43 Osler M, Prescott E, Grønbæk M, et al. Income inequality, individual income, and mortality in Danish adults: analysis of pooled data from two cohort studies. BMJ 2002;324:13-16.

44 Harding S, Maxwell R. Differences in mortality of migrants. In: Drever F Whitehead M, eds. Health inequalities. London: The Stationery Office, 1997

45 Brimblecombe N, Dorling D, Shaw M. Migration and geographical inequalities in health in Britain. Soc Sci Med 2000;50:861-78.

46 Woodward A, Kawachi I. Why reduce health inequalities? J Epidemiol Community Health 2000;54:923-9.

47 Mackenbach JP, Bakker MJ. Reducing inequalities in health: the European experience. London: Routledge, 2002.

48 Carvel J. Milburn plans to cut death rate of poor. Guardian 2001;Feb 28.

49 Zöllner H. National policies for reducing social inequalities in health in Europe. Scand J Public Health 2002;30:6-11.

50 Armitage M, Povall S. Practical issues in translating evidence into policy and practice. In: Oliver A, Exworthy $M$, eds. Health Inequalities: evidence, policy and implementation. London: The Nuffield Trust, 2003.

51 Hanlon P, Walsh D, Buchanan D, et al. Chasing the Scottish effect. Glasgow: Public Health Institute of Scotland, 2001.

52 Newman C. Scottish spending gap with England persists. Financial Times 2002;May 15.

53 Summers D. Backing for Barnett as Foulkes attacks SNP. Herald 2002;Jan 16. 